Tian, Qing; Lowe, K. Todd; Simpson, Roger L.

\title{
A Laser-Based Optical Approach for Measuring Scour Deptharound Hydraulic Structures
}

Verfügbar unter / Available at:

https://hdl.handle.net/20.500.11970/100224

Vorgeschlagene Zitierweise / Suggested citation:

Tian, Qing; Lowe, K. Todd; Simpson, Roger L. (2010): A Laser-Based Optical Approach for Measuring Scour Deptharound Hydraulic Structures. In: Burns, Susan E.; Bhatia, Shobha K.; Avila, Catherine M. C.; Hunt, Beatrice E. (Hg.): Proceedings 5th International Conference on Scour and Erosion (ICSE-5), November 7-10, 2010, San Francisco, USA. Reston, Va.: American Society of Civil Engineers. S. 787-796. 


\title{
A LASER-BASED OPTICAL APPROACH FOR MEASURING SCOUR DEPTH AROUND HYDRAULIC STRUCTURES
}

\author{
Qing $\operatorname{Tian}^{1}$, K. Todd Lowe ${ }^{1}$, and Roger L. Simpson ${ }^{1}$, Member, ASCE, P.E. \\ ${ }^{1}$ Applied University Research, Inc., 605 Preston Ave., Blacksburg, VA 24060; email: \\ aur(waurinc.com
}

\begin{abstract}
This paper describes a method using laser-based optical instrumentation to measure scour depth around hydraulic structures after flume tests. This laser-based optical approach utilizes a laser light sheet and digital camera. This method is nonintrusive, easy to setup and has high spatial resolution. A validation case of measuring a 3-D concave shape with known dimensions was conducted to evaluate the uncertainty of the proposed methodology. The intrinsic uncertainty limit represented by the laser sheet thickness is reached, and this simple procedure is suitable for obtaining meaningful results with an acceptable level of accuracy. The performance of applying a hooked collar as a scour countermeasure around a circular pier, rectangular pier and 2-D streamlined pier was studied and tested inside a flume. The scour depth data were measured and recorded with the described laser-based optical technique. The hooked collar reduced the maximum local scour depth by $60 \%$ at the optimal collar location; but it was importantly observed that this location strongly depends upon the local flow conditions such as the incoming flow speed, flow depth and pier width.
\end{abstract}

\section{INTRODUCTION}

Removal of riverbed substrate around bridge pier footings is known as scour. Excessive scour around bridge piers due to the large-scale unsteadiness and shedding of coherent vortices is the cause of failure of many bridges around the world (Batcho, 2001). Over the past decades, the local scouring mechanism around the circular pier has been studied intensively, well understood and documented. The horseshoe vortex and wake shedding vortices were identified as the major causes for the local scour around circular piers as described by Breusers et al. (1977), Melville (1975) and Dargahi (1990). The three-dimensional boundary layer separation due to large pressure gradients around a bridge pier is accompanied by large-scale vortices, characterized with intense turbulence, unsteadiness, shear stress and vorticity (Simpson, 2001).

Along with the understanding of local scour, various different methods for controlling local scour have been proposed. Bridge pier scour countermeasure techniques can be classified into three classes (Lagasse, et al. 2001), which are hydraulic countermeasures to enhance the resistance ability of the bed material to scour, structural countermeasures to reduce the power of the scour agents by modifying the local flow condition around the hydraulic structures, and scour monitoring. The structural countermeasures such as pier shape modifications and collars are primarily used to minimize local scour. The pier shape modifications 
mentioned here refer to the bridge piers with streamlined cross sections. The performance of the streamlined piers on reducing local scour was studied by Laursen and Toch (1956) and Chabert and Engeldinger (1956). The conclusions were made that the streamlined piers greatly reduced the maximum scour depth. However, they also pointed out that the effectiveness of the streamlined piers on controlling local scour became questionable when the pier was not aligned with the flow, especially for the piers at a large angle of attack. This observation is intensified for piers with large length-to-width ratio. The results reported in the literature by Chabert and Engeldinger (1956), Thomas (1967), Tanaka and Yano (1967), Neill (1973), Ettema (1980) and Chiew (1992) showed that placing a collar or caisson around a bridge pier reduced the depth of scour. Thomas (1967), Tanaka and Yano (1967) and Dargahi (1990) also demonstrated that in order to be effective on controlling local scour, the collar has to be inside the separated flow region close to the riverbed and the collar diameter to pier diameter ratio has to be more than 3 .

A typical real-world bridge pier with a diameter of some few meters yields flat collar diameters for effective scour control which are too large to be practical. Therefore, Chen et al. (2007) came up with the "hooked" collar idea. In their design, Chen et al. used a small diameter horizontal collar with a vertically oriented fence that forms an annulus around the periphery of the horizontal collar. The vertical "hook" section acts to prevent the downward jet flow of the horseshoe vortex that enhances local scour. The horizontal collar section has much smaller diameter than the flat collar necessary to mitigate local scour. Their results did show the improvement of local scour with the hooked collar at the optimal location along the vertical axis of the pier. The present work expands upon the work reported by Chen et al. The objectives are to investigate, by means of flow visualization and laser-based scour depth measurements, the effectiveness of the hooked collar design for different pier shapes and the coupling of the incoming flow and bed conditions, such as incoming flow speed, flow depth and sediment size, with the local scour observed.

Along with the research related to the scour countermeasures, the need of developing high spatial resolution and nonintrusive measurement instrumentation for studying sediment bed erosion becomes imperative. Traditional methods such as point gauges are intrusive and time consuming to use since they can only perform point-by-point measurements. Baglio and Foti (2003) developed a 3-D stereoscopictype image processing method to measure three-dimensional coordinates of a scoured sediment bed surface. To do so, two video cameras at different viewing angles were applied during the process. Calibration was required for this process in order to get the coordinate transformation matrix. Younkin and Hill (2009) applied a planar laser sheet to illuminate the granular bed to capture the evolution of the sediment bed scour due to horizontal wall jet. In this paper, a simplified nonintrusive laser-based optical technique is proposed for rapidly measuring a scour hole. A 2-D laser sheet profile intersecting a scour hole is recorded with a digital camera and transformed from the image coordinates to the objective coordinates through a simple transformation formula. This simple technique affords detailed bed contour measurements in a fraction of the time required to probe the contoured surface mechanically. 


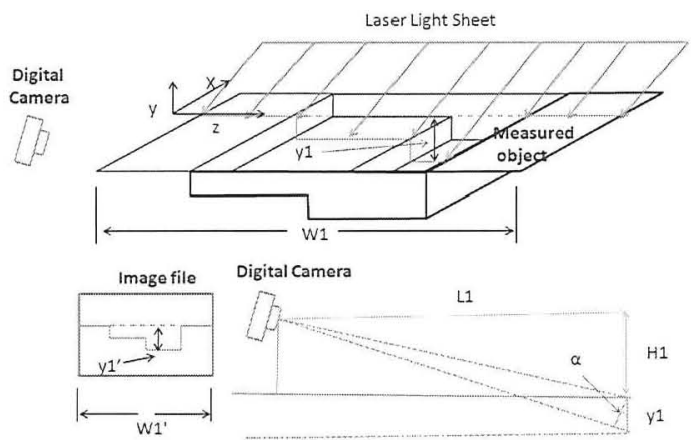

Figure 1. Laser optical approach for 2-D scour depth measurement.

\section{MEASUREMENT METHODOLOGY}

\section{Laser-based Optical Approach for Measuring Scour Depth}

A laser-based optical technique is applied for rapidly obtaining detailed bed elevation contours for scour testing. In the technique (figure 1), a laser light sheet is progressively positioned to illuminate slices of a scour hole from a flume test. The intersection of the laser sheet with the bed surface appears as a curved line to a viewer positioned out of the plane of the sheet. The image of this curved line is recorded with a digital camera, and post-processed using spatial calibration factors to convert the pixel coordinates of the line to surface elevations. Perspective distortion is eliminated through proper alignment of the camera relative to the sheet and by applying a geometric transformation from image coordinates to actual scour depth during postprocessing. The following equations (1-3) are used as the transformation formulas from the image coordinates to the objective coordinates under the condition that $\mathrm{L} 1$ and $\mathrm{H} 1$ are much greater than $\mathrm{y} 1$. The equation (1) may be solved iteratively to obtain the scour depth given the instrument system parameters. The curved line profile from the laser sheet intersection with the scour hole is on the $y-z$ plane in the objective coordinate as shown in figure 1 and the flat intersection line with the initial bed level is aligned with the z-axis. The third dimension coordinates of the curved line profile along the x-axis, which are constant, can be measured, and recorded manually. Therefore, the 3-D spatial coordinates of a scoured bed surface can be measured and reconstructed with only one still or video camera.

$$
\begin{gathered}
y 1 \approx \frac{y 1^{\prime} \times M}{\cos (\alpha)} \text { and } \tan (\alpha) \approx \frac{y 1+H 1}{L 1}, \text { if } L 1, H 1 \gg y 1 \\
z 1=z 1^{\prime} \times M \\
M=\frac{W 1}{W 1^{\prime}}
\end{gathered}
$$

Where $\mathrm{M}$ is the calibration factor from pixel to the objective dimension before the perspective correction; $y 1$ and $z 1$ are the coordinates of the curved line profile in the objective coordinate; y1' and $\mathrm{zl}^{\prime}$ are the coordinates of the curved line profile in the 
image coordinate; $\mathrm{W} 1$ is the known width of the spanwise reference line in the objective coordinate; Wl'is the width of the spanwise reference line in the image coordinate; L1 is the horizontal distance between the laser sheet plane and the camera; and $\mathrm{H} 1$ is the vertical distance between the camera and the initial sediment bed level.

\section{Discussion of the Uncertainty of the Developed Measurement System}

A validation case of measuring the outline of a PVC coupler with known geometry is performed to evaluate the uncertainty of the developed measurement system. Figure 2 demonstrates the quality of the agreement between the measured and true value of the outline. The standard deviation of the difference between the measured and true value is about $0.5 \mathrm{~mm}$. Given 21 to 1 odds, the uncertainty calculated as $\pm 2 \sigma$ is about $1.0 \mathrm{~mm}$. The actual thickness of the laser sheet is about $1.5 \mathrm{~mm}$. Therefore, the measured uncertainty is very close to the thickness of the laser sheet.

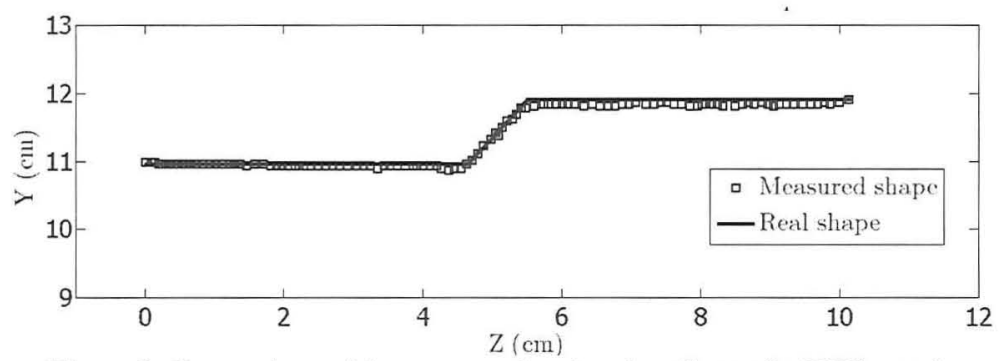

Figure 2. Comparison of the measured and real outlines of a PVC coupler.

\section{EXPERIMENTAL SETUP AND PROCEDURES}

\section{Flume}

The water flume facility was designed and constructed at the Applied University Research, Inc (AUR) laboratory in Radford, Virginia. The straight test section has a clear acrylic sidewall, and is about $2.44 \mathrm{~m}$ long and $1.22 \mathrm{~m}$ wide. The sidewall height is about $0.19 \mathrm{~m}$ and the water depth used for the current tests is 0.165 $\mathrm{m}$. A layer of pea gravel bed was placed in the gravel tank. The pea gravel used for local sour tests has a specific gravity of three and is between $3.2 \mathrm{~mm}$ and $6.4 \mathrm{~mm}$ in size. The flume experiments were run at a nominal speed of $0.64 \pm 0.03 \mathrm{~m} / \mathrm{s}$. The selected test speed produced an incipient scour conditioon for the pea gravel without any pier present. The influence of the sediment size on scour depth was studied by Ettema (1980); and it was found that for gravel size greater than $0.7 \mathrm{~mm}$, there was a critical value of 18 for the pier width to gravel size ratio. If that ratio is above the critical value, the ratio of maximum scour depth to pier width reaches to a constant value. The corresponding pier width to gravel size ratio in following flume tests ranges between 12 and 24, with a mean value of 18 . Therefore, there is little or no influence of gravel size on the maximum scour depths measured. The inflow boundary layer profile was measured with a Pitot-static probe and a U-manometer. 
The results are presented in figure 3 . The free surface boundary profile essentially follows the expected law of the wall (Elder 1959).

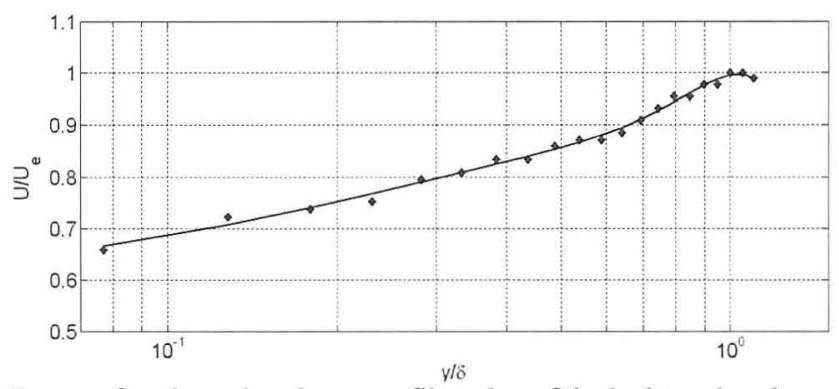

Figure 3. Free surface boundary layer profile, where $\delta$ is the boundary layer thickness at $99.5 \%$ of maximum velocity.

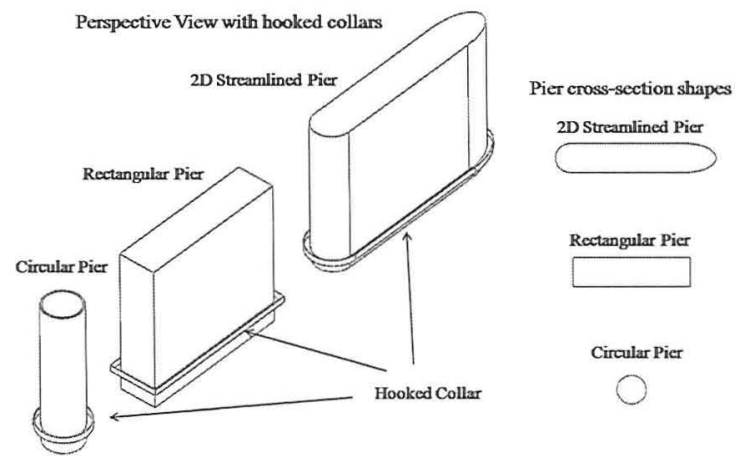

Figure 4. Sketch of the bridge pier models.

\section{Experimental Test Models, Flow Cases, and Procedures}

The bridge pier models with hooked collars are sketched in figure 4 . Three different pier shapes have been tested: a circular pier, a rectangular pier and a 2-D streamlined pier. The length-to-width ratio of the rectangular pier is 4:1. The 2-D streamlined pier has a circular front nose and elliptical rear nose; and the middle section is a rectangle with 4:1 length-to-width ratio. The width of the pier models is $0.076 \mathrm{~m}$. Each sheet-metal hooked collar has a flat horizontal bottom and a vertical surface. Hooked collars were used in some of the current tests. The design is based upon the work reported by Chen et al. (2007), as described in the introduction. The width and depth of the hooked collar are both $0.0127 \mathrm{~m}$. For each pier model, the case without the hooked collar was tested and used as the reference for studying the effectiveness of the hooked collar. The hooked collar was placed at three different locations: $\mathrm{h}_{\mathrm{c}} / \mathrm{D}=0,0.165$ and 0.33 or each pier model. All tests-with or without hooked collars-were run with a water depth of $h_{w} / D=2.17$ 


\section{EXPERIMENTAL RESULTS AND DISCUSSION}

\section{Circular Pier Results}

The bed elevation contour around a circular pier without the hooked collar was measured with the laser-based optical technique. The non-equidistantly-sampled scour depth data were interpolated onto a $6.5 \mathrm{~mm}$ by $6.5 \mathrm{~mm}$ square cell grid with a linear triangle-based interpolation. Scour depth contour results are presented in figure 5.a. The color in the contour represents the variation of the bed level. The scour pattern results are consistent with previous studies such as the work of Tanaka and Yano (1967) and of Lin (1993). Local scour was observed immediately upon initiation of the test. Before reaching equilibrium, the gravel in the separated flow region became loose, was carried away from the bed and was deposited downstream. As expected from much previous work, flow visualizations (in this case, performed using a single tuft) indicated the presence of a strong horseshoe vortex around the windward portion of the pier and wake shedding vortices behind the circular pier. The chaotic "bimodal" flow switching behavior of the horseshoe vortex described by Devenport and Simpson (1990) was also qualitatively observed in the tuft visualizations.

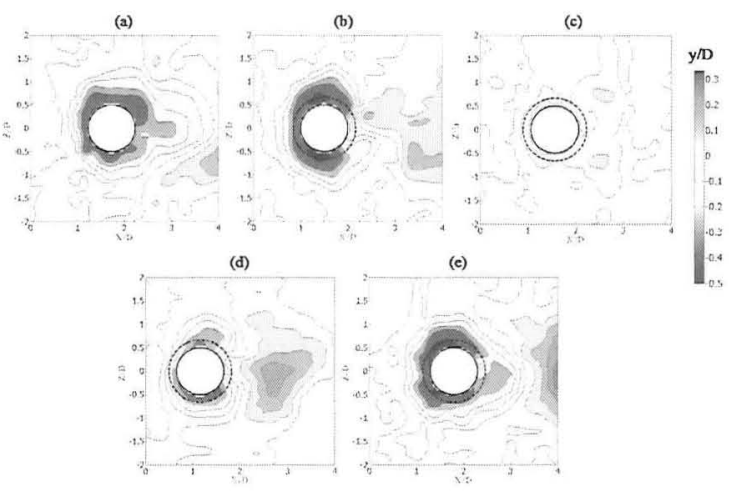

Figure 5. Measured final bed elevation contours around a circular cylinder pier with $h_{w} / D=2.17$ (a: no hooked collar; b: $h_{c} / D=0 ; c: h_{c} / D=0.165 ; d: h_{c} / D=0.33 ;$ and $e: h_{c} / D$ $=0.72$ ).

The results with the hooked collar located at $h_{c} / D=0,0.165,0.33$ and 0.72 are presented in figures 5.b-e. Results were obtained after the local scour rate appeared to reach zero. The hooked collar is plotted with a dashed line. For the cases $h_{c} / D=0$, 0.165 and 0.33 , local scour started very slowly around and under the hooked collar. The flow visualization showed that the downwash motion around the pier and under the hook was very chaotic. Unlike the case without the collar when scour was immediately observable, it took more than $15118 \mathrm{D} / \mathrm{U}_{\mathrm{e}}$ normalized time units before the local scour hole became observable, and then the local scour rate increased 
dramatically. The scour rate later decreased and approached zero by $45354 \mathrm{D} / \mathrm{U}_{\mathrm{e}}$, time units after test initiation of the test case. The location $h_{c} / D=0.165$, was optimal, as it yielded the greatest reduction of local scour. Maximum scour depth was reduced by $65 \%$, and there was almost no scour appearing in the wake region. The flow visualization results showed that the separated flow under the bottom edge of the hook flowed counter to the dominant mean vortical motion of the horseshoe vortex upstream of the circular pier, and the downwash motion along the pier was very weak. In contrast to the $h_{c} / D=0.165$ case, the $h_{c} / D=0.72$ collar location had almost no effect on local scour. The scour pattern for $h_{c} / D=0.72$ is very similar to the one without the collar and the maximum scour depth is about $0.45 \mathrm{D}$.

Chen et al. (2007) conducted a series of flume tests with hooked collars. The circular pier diameter and hooked collar dimension are very similar to current case. Their results did show reduction in the local scour with the hooked collar when placed at the optimal location. However, the specific optimal collar locations for these two cases are quite different. Chen's study showed that the best collar location was at $\mathrm{h}_{\mathrm{c}} / \mathrm{D}=0.88$, while the current study yielded a value of 0.165 for optimal performance. This is mainly due to the difference in the incoming flow speed. The flow speed under the incipient scour condition in Chen's tests is about $0.24 \mathrm{~m} / \mathrm{s}$ due to the relatively fine gravel, while the current test speed is $0.63 \mathrm{~m} / \mathrm{s}$. Such results indicate the most important challenge in practically implementing the hooked collar approach for reducing local scour.

(a)

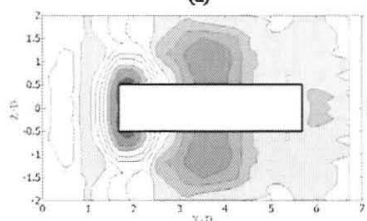

(c)

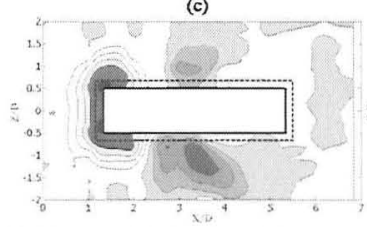

(b)

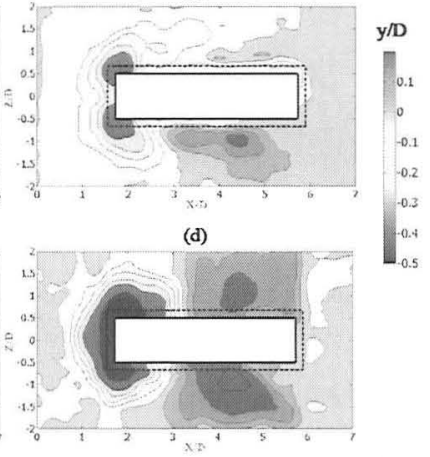

Figure 5. Measured final bed elevation contours around a rectangular pier with $h_{w} / D=2.17$ (a: no hooked collar; b: $h_{c} / D=0 ; c: h_{c} / D=0.165$; and $d: h_{c} / D=0.33$ ).

\section{Rectangular Pier Results}

The rectangular pier with length-to-width ratio equal to four, which is representative of a common class of bridge piers, was tested in the current study. The rectangular pier was installed at the middle of the test section. Under the influence of the horseshoe vortex, a deep scour hole appeared at the front nose of the rectangular pier at zero angle of attack, as shown in figure 6.a. The color in the contour represents the variation of the bed level. The maximum scour depth is about $0.4 \mathrm{D}$ around the nose and scour behind the pier is negligible. The above scour pattern and observations 
are consistent with the experimental test results by Briaud et al. (2004). In that work, series of flume tests of rectangular piers were conducted to study pier shape effects (different length-to-width ratios) and angle of attack effect on local scour. It was found that for rectangular piers with aspect ratios greater than 4 , the scour hole only appeared on the windward side, and no scour was observed in the wake region.

The test results for the rectangular pier with hooked collar at $h_{c} / D=0,0.165$ and 0.33 are presented in figures 6.b-d. Similar to the case without the collar, gravels on the windward side were scoured out and one big scour hole was formed. As the collar was moved further away from the gravel bed, the local scour area and maximum scour depth were increased. There was no optimal location for hooked collar. Unlike the circular pier, the hooked collar around the rectangular pier actually increased local scour area and maximum scour depth. The hooked collar did not work as a scour countermeasure for the rectangular pier. There was no significant change in scour rate and local scour was observed right after the flume experiments were begun for each case. Results indicate that the corner separation around the rectangular hook is the main cause for the difference in performance as a scour countermeasure.

(a)

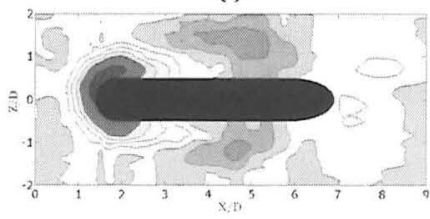

(c)

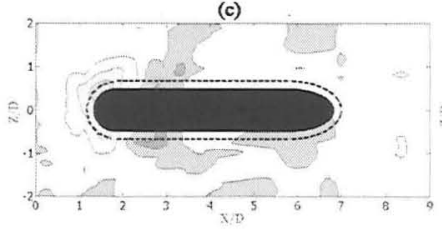

(b)

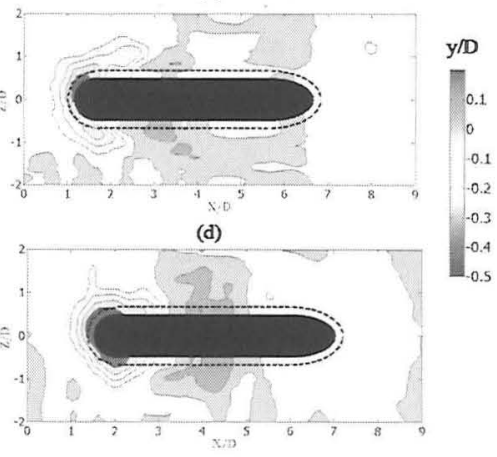

Figure 7. Measured final bed elevation contour around a 2-D streamlined pier with $\mathrm{h}_{\mathrm{w}} / \mathrm{D}=2.17$ (a: no hooked collar; $\mathrm{b}: \mathrm{h}_{\mathrm{c}} / \mathrm{D}=0 ; \mathrm{c}: \mathrm{h}_{\mathrm{c}} / \mathrm{D}=0.165$; and $\mathrm{d}: \mathrm{h}_{\mathrm{c}} / \mathrm{D}=0.33$ ).

\section{2-D Streamlined Pier Results}

The 2-D streamlined pier has a half-circular front nose and a half-elliptical rear nose, and the middle section is a rectangle with 4:1 length-to-width ratio. The hooked collar is in the same shape as the streamlined pier and plotted with dash line as shown in figure 7 . The hook dimensions normalized by the pier width are the same as hooked collars used for the circular and rectangular piers already discussed. In figure 7.a, a large scour hole developed under the influence of the horseshoe vortex around the circular front nose without the collar. The maximum scour depth is about $0.5 \mathrm{D}$. The scour hole is in the similar shape as for the circular pier without the collar and has a maximum width of $2 \mathrm{D}$.

The test result for the streamlined pier with the hooked collar installed so that the bottom rests on the initial gravel bed is included in figure 7.b. It does show some improvement on local scour by reducing maximum scour depth and its area. The 
maximum scour depth is reduced from $0.5 \mathrm{D}$ without the hooked collar to $0.35 \mathrm{D}$ and concentrates in a smaller region. The hooked collar also caused a slightly more scour in the spanwise direction around the junction of the circular and straight sections. Figure 7.c shows that the best hook location for this pier model is located at $h_{c} / D=0.165$, which is also consistent with the location for the circular pier. The maximum scour depth is reduced to $0.2 \mathrm{D}$. Moving the collar further away from the bed, the local scour condition became worse as shown in Figure 7.d. Very slow scour rate was observed during the above collar tests. At the optimal location, the hooked collar reduced the maximum scour depth by $60 \%$.

\section{CONCLUSIONS}

A nonintrusive method utilizing a laser light sheet and digital camera to measure scoured sediment bed surface around hydraulic structures after flume tests is presented in this paper. The major advantages of this method are that it is nonintrusive, spatially resolved, easy to setup and efficient for making whole-surface elevation measurements. The uncertainty analysis shows that the intrinsic uncertainty limit represented by the laser sheet thickness is reached. This simple procedure is suitable for obtaining meaningful results with an acceptable level of accuracy.

The flume test results of hooked collars around a circular pier, rectangular pier and 2-D streamlined pier demonstrate that the hooked collars at the optimal locations reduced the maximum scour depth by $60-65 \%$ for the circular pier and $2-\mathrm{D}$ streamline shaped pier. In most of the cases studied, the hooked collars reduced the local sediment transport rate. However, the results also show that the optimal collar location greatly depends on and varies with the incoming flow conditions and other local conditions, such as the flow speed and pier width. For these reasons, the hooked collar becomes difficult to adopt in a real situation. The hooked collar did not work at all for the rectangular pier and even caused more severe local scour, because of the corner separation around the rectangular hooked collar.

\section{References}

Baglio, S., \& Foti, E. (2003). Non-Invasive Measurements to Analyze Sandy Bed Evolution Under Sea Waves Action. IEEE TRANSACTIONS ON INSTRUMENTATION AND MEASUREMENT, 52 (3), 762-770.

Batcho, Paul F. Method and apparatus for mitigating junction flows. US: Patent 6186445 , 2001.

Breusers, H., Nicollet, G., \& Shen, H. (1977). Local Scour Around Cylindrical Piers. Journal of Hydraulic Research , 15 (3), 211-252.

Briaud, J.-L., Chen, H. C., Nurtjahyo, P., \& Wang, J. (2004). Pier and Contraction Scour in Cohesive Soils. Washington, D. C.: NCHRP Report 516.

Chabert, J., \& Engeldinger, P. (1956). Etude des affouillements autour des piles des ponts. Chatou, France: Laboratoire National d'Hydraulique.

Chen, S.-C., Wang, D.-Y., Chou, H.-T., \& Yen, S.-C. (2007). The efficacy of hooked-collar on reducing bridge pier scour. Journal of Taiwan Water Conervancy, 55, 26-37.

Chiew, Y.-M. (1992). Scour Protection at Bridge Piers. Journal of Hydraulic Engineering , $118(9), 1260-1269$.

Dargahi, B. (1990). Controlling Mechanism of Local Scouring. Journal of Hydraulic Engineering , 116 (10), 1197-1214. 
Devenport, W. J., \& Simpson, R. L. (1990). Time-dependent and time-averaged turbulence structure near the nose of a wing-body junction. Journal of Fluid Mechanics , 210, 23-55.

Elder, J. (1959). The dispersion of marked fluid in turbulent shear flow. Journal of Fluid Mechanics, 544-560.

Ettema, R. (1980). Scour at Bridge Piers. University of Aurcland, New zealand, School of Engineering. Report NO. 216.

Lagasse, P., Zevenbergen, L., Schall, J., \& Clopper, P. (2001). Bridge Scour and Stream Instability Countermeasures. FHWA Technical Report Documentation Hydraulic Engineering Circular No. 23.

Laursen, E. M., \& Toch, A. (1956). Scour Around Bridge Piers and Abutments. Iowa Institute of Hydraulic Research.

Lin, G. H. (1993). Study on the Local Scour around Cylindrical Bridge Piers. Feng-Chia University, Taichung, Taiwan: M.S. Thesis.

Melville, B. W. (1975). Local scour at bridge sites. Report NO. 117 The University of Auckland, School of Engineering, New Zealand.

Neill, C. R. (1973). Guide to bridge hydraulics. Roads and Transportation Association of Canada, University of Toronto Press, Toronto, Canada.

Simpson, R. L. (2001). Junction Flows. Annual Review of Fluid Mechanics, Vol. 33: 415443.

Tanaka, S., \& Yano, M. (1967). Local scour around a circular cylinder. Proc.12th Congress I.A.H.R., (pp. 193-201).

Thomas, Z. (1967). An interesting hydraulic effect occurring at local scour. Proc.12th Congress I.A.H.R., (pp. 125-134).

Younkin, B., \& Hill, D. (2009). Rapid Profiling of an Evolving Bed Form Using Planar Laser Sheet Illumination. Journal of Hydraulic Engineering , 135 (10), 852-856.

\section{NOTATION}

The following symbols are used in the paper

$\alpha=$ angle between the camera optical axis and the initial sediment bed level;

$\delta=$ boundary layer thickness

$\mathrm{D}=$ diameter or width of pier models;

$\mathrm{h}_{\mathrm{c}}=$ vertical location for the hooked collars;

$h_{w}=$ water depth inside the flume test section;

$H 1=$ vertical distance from the digital camera to the initial sediment bed level;

$L 1=$ horizontal distance between the laser sheet plane to the digital camera;

$M=$ calibration factor from pixel to the objective dimension;

$U_{e}=$ Free surface speed;

$W 1=$ width of the spanwise reference line in the objective coordinate;

$W 1^{\prime}=$ width in pixels of the spanwise reference line in the image coordinate;

$x 1^{\prime}, y 1^{\prime}$ and $z 1^{\prime}$ : coordinates in the image coordinate; and

$x 1, y 1$ and $\mathrm{z} 1$ : coordinates in the objective coordinate 